\title{
RADIOCARBON AND STABLE CARBON ISOTOPES IN TWO SOIL PROFILES FROM NORTHEAST INDIA
}

\author{
Amzad H Laskar' $•$ M G Yadava • R Ramesh \\ Geosciences Division, Physical Research Laboratory, Ahmedabad 380009, India.
}

\begin{abstract}
Two soil profiles from northeast India, one from Bakrihawar, an agricultural land, and the other from Chandipur, a virgin hilly area from Assam, are investigated to understand the organic carbon dynamics of the area. Due to frequent flooding, the Bakrihawar soil has accumulated a higher clay content than that of Chandipur. The carbon content is less than $1 \%$ by weight in both the sites. The higher clay content is responsible for relatively more soil organic carbon at Bakrihawar. The mean $\delta^{13} \mathrm{C}$ values at both sites reflect the values of the overlying vegetation. At Bakrihawar, both rice cultivation $\left(\mathrm{C}_{3}\right)$ and natural $\mathrm{C}_{4}$ grasses contribute to higher mean enriched values of ${ }^{13} \mathrm{C}$ relative to Chandipur, where the surface vegetation is mostly of $\mathrm{C}_{3}$ type. The turnover time of organic carbon, estimated using the residual radiocarbon content, depends strongly on the soil particle size distribution, especially the clay content (i.e. it increases with clay content). To the best of our knowledge, this is the first soil carbon dynamics study of its kind from northeast India.
\end{abstract}

\section{INTRODUCTION}

Understanding the mechanistic controls over the fate, transport, and turnover times of organic carbon in soils is important because it is a significant carbon reservoir with a potential role in the global climate. The dynamics of soil organic carbon (SOC), factors governing the turnover time of SOC, and variation with depth in many tropical regions are not clearly understood. It is believed that the turnover time of the organic carbon in tropical soils is less than that of boreal and temperate soils (Raich and Schlesinger 1992; Schimel et al. 1994; Thompson et al. 1996; Torn et al. 2009).

Stable carbon isotopic composition $\left(\delta^{13} \mathrm{C}\right)$ of soil and sedimentary organic matter has been widely used in paleoclimatic studies (Sukumar et al. 1993; Biedenbender et al. 2004; Leavitt et al. 2007; Wynn and Bird 2008; Laskar et al. 2010; Zhong et al. 2010). In an undisturbed site, under humid and low temperature conditions, $\mathrm{C}_{3}$ vegetation dominates, with $\delta^{13} \mathrm{C}$ values between $-19 \%$ and $-32 \%$ and a mean of $-27 \%$. While in a warm/arid climate, $\mathrm{C}_{4}$ plants are abundant, with $\delta^{13} \mathrm{C}$ values from $-9 \%$ to $-19 \%$ and a mean of $-13 \%$ (Deines 1980 ). Kohn (2010) showed that the $\delta^{13} \mathrm{C}$ of $\mathrm{C}_{3}$ vegetation increases with the decrease in mean annual precipitation. The average $\delta^{13} \mathrm{C}$ value of $\mathrm{C}_{3}$ vegetation estimated by Kohn (2010) is $-28.5 \%$ considering the Northern Hemisphere tropical and midlatitude biomass. At any place, SOC carries the $\delta^{13} \mathrm{C}$ signature of the mixed vegetation, which is present at the time of pedogenesis (Balesdent et al. 1993; McPhearson et al. 1993), although percolation of fresh material cannot be ruled out totally. A carbon isotopic fractionation of up to $2-4 \%$ during humification and microbial decomposition has been reported, mainly in the upper soil layers (Quade and Cerling 1995; Accoe et al. 2002; Wynn et al. 2006; Bostörm et al. 2007), but this is small compared to the difference between the mean $\delta^{13} \mathrm{C}$ values of the 2 major plant types $\left(\mathrm{C}_{3}\right.$ and $\mathrm{C}_{4}$ ). Radiocarbon and stable carbon isotopes are very good tools to study the soil carbon dynamics and their driving mechanisms (Torn et al. 2009; Trumbore 2009).

Detailed quantitative studies of carbon dynamics in the tropical soils from India are very limited (Becker-Heidmann and Scharpenseel 1989; Caner et al. 2007). Therefore, this paper presents the results of concentration, ${ }^{14} \mathrm{C}$, and $\delta^{13} \mathrm{C}$ measurements made on the $\mathrm{SOC}$ of 2 soil sections from an unexamined region in northeast India. The aims of the present study are (i) to determine the difference between the organic carbon content in the tropical agricultural and undisturbed soils; (ii) to use soil $\delta^{13} \mathrm{C}$ and ${ }^{14} \mathrm{C}$ variations to understand SOC dynamics, especially its turnover time; and (iii) to better understand the factors influencing the variability of $\delta^{13} \mathrm{C}$ in a soil profile.

${ }^{1}$ Corresponding author. Email: amzad@prl.res.in. 


\section{STUDY AREA AND SAMPLING}

Soil samples were collected in May 2009 from 2 sites $\sim 5 \mathrm{~km}$ apart: (1) an agricultural land at Bakrihawar (henceforth referred to as BR) and (2) Chandipur, an undisturbed hilly region (henceforth referred to as $\mathrm{CH}$ ). Both are located in the Hailakandi district (Figure $1 ; 24^{\circ} 41^{\prime} \mathrm{N}, 92^{\circ} 34^{\prime} \mathrm{E} ; 21 \mathrm{~m}$ asl) of Assam, northeast India. The long-term mean annual precipitation and temperature in the sampled area are $\sim 3200 \mathrm{~mm} / \mathrm{yr}$ and $\sim 20^{\circ} \mathrm{C}$, respectively, obtained from the nearest meteorological station, Silchar (India Meteorology Department 1999). The district is located $200 \mathrm{~km}$ south of the world's heaviest rainfall regions, Cherrapunji and Mawsynram. It receives most of its annual precipitation ( $\sim 80 \%)$ during the southwest monsoon (June to September). Soils at both the sites are free of carbonates, confirmed using $10 \% \mathrm{HCl}$. Individual descriptions of the 2 sites are given below.

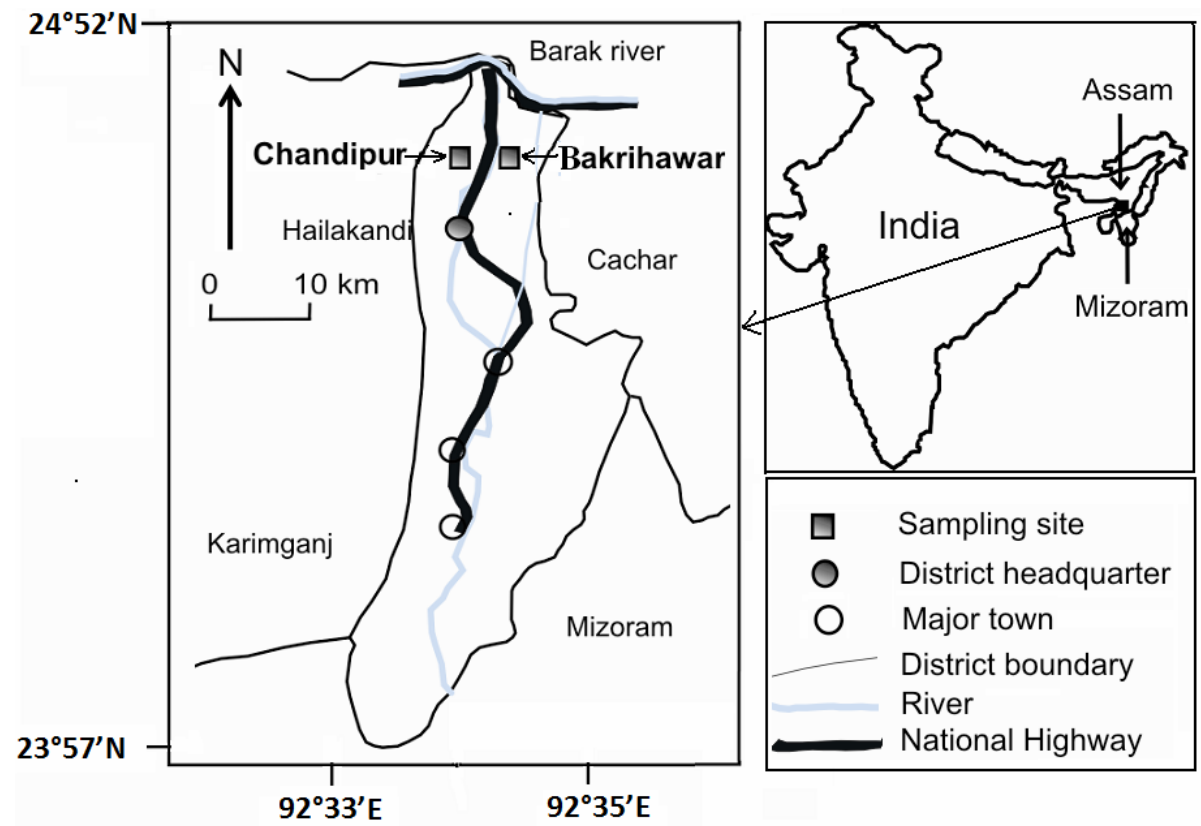

Figure 1 Map showing the Hailakandi district and the locations of the study sites

\section{Bakrihawar (BR)}

This is a flat agricultural land a few tens of $\mathrm{km}^{2}$ wide and is locally known as hawar (open land). It is well drained through small water channels and is at present being used for cultivating paddy, from July to December. The rest of the year, the land remains a grazing field. Almost every year, during heavy rains, the site is flooded. Occasional large-scale flooding is also observed (about once every $\sim 5 \mathrm{yr}$ ). The soil is very rich in clay, gray in color with no distinct lamination (Figure 2). The soils are Entisols, alluvial in nature and classified as silty clay. During heavy floods, sediments from higher elevation (the southern part of Hailakandi and Mizoram state) are brought and deposited in this region.

\section{Chandipur (CH)}

This site is a hilly region with insignificant anthropogenic activity. The present vegetation is dominated mainly by shrubs and bamboo trees, however, with a very low spatial density. The site is well 


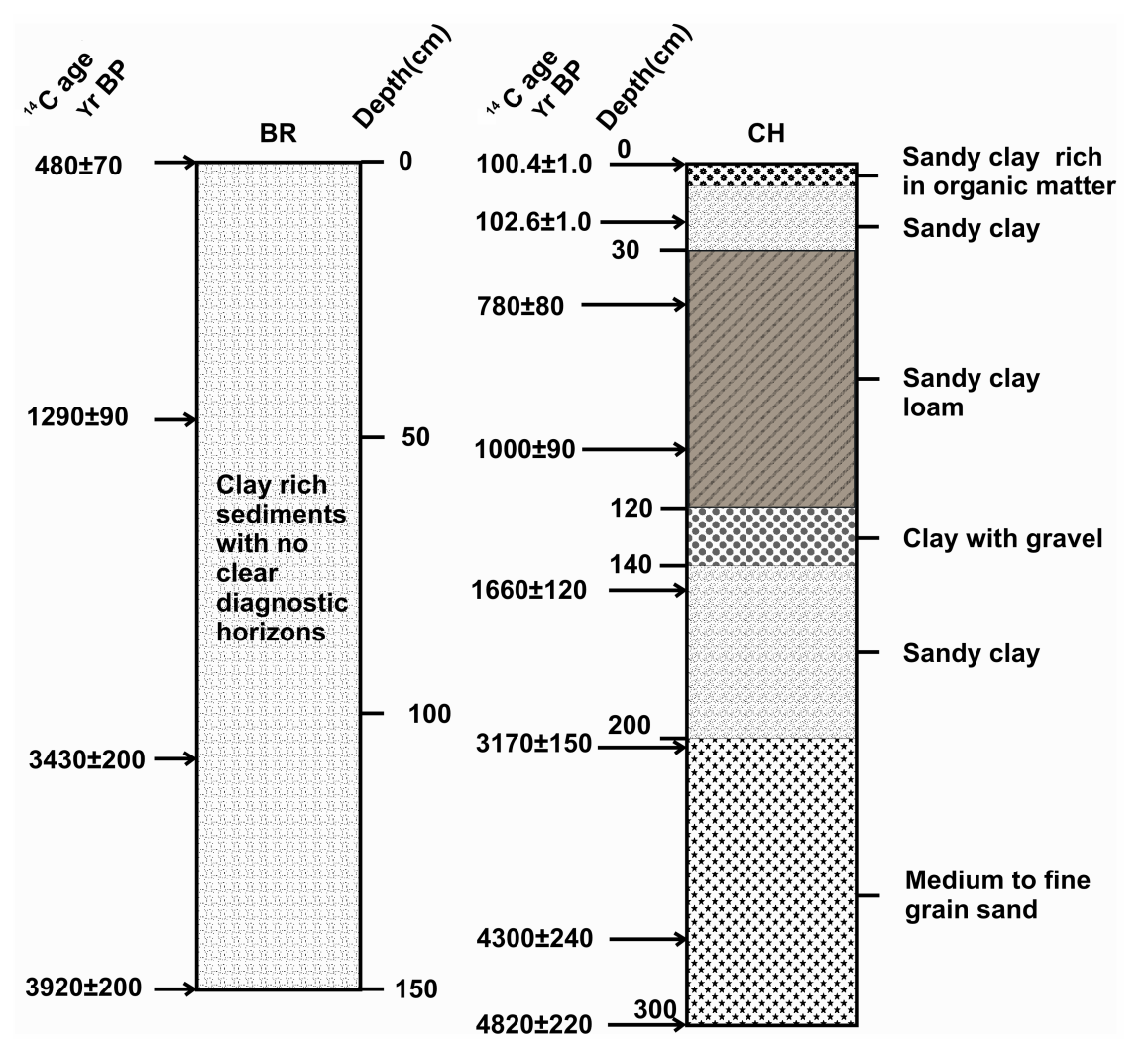

Figure 2 Lithologs of the 2 soil profiles. ${ }^{14} \mathrm{C}$ ages at various depths are shown on the left $(\mathrm{BR}=\mathrm{Bakri}-$ hawar; $\mathrm{CH}=$ Chandipur).

drained by a small stream flowing down to the foothills. The soils are Spodosols, appearing reddishbrown with well-developed distinct laminations (Figure 2) and are classified as sandy loam. The samples were collected from the whole profile covering the 3 soil horizons: A (depth 0-50 cm); B $(50-200 \mathrm{~cm})$; and $\mathrm{C}(200-300 \mathrm{~cm})$. The $\mathrm{O}$ horizon is absent in the site.

\section{METHODS}

Samples from BR were collected by digging a $\sim 1.5$-m-deep pit and those of $\mathrm{CH}$, from a $\sim 3$-m-high cliff section. A $\sim 300$-g sample was recovered from a $\sim 2$-cm-thick layer along the profile at several depths (Table 1). These were brought to the laboratory in sealed plastic bags, and later dried at $70{ }^{\circ} \mathrm{C}$ for $\sim 24 \mathrm{hr}$. Before analyses, rootlets and their fragments, which could be relatively modern, were removed manually. The remaining samples were thoroughly homogenized and filtered through a $2-$ $\mathrm{mm}$ sieve. Samples of modern vegetation and grasses present were also collected from the 2 sites for determining their $\delta^{13} \mathrm{C}$ (Table 1).

All samples were washed with $10 \% \mathrm{HCl}$ to remove the carbonate fraction if present in trace amount. The samples were neutralized with distilled water and dried. Weighed amounts of dried samples were combusted in excess oxygen at $900{ }^{\circ} \mathrm{C}$ to convert $\mathrm{SOC}$ to $\mathrm{CO}_{2}$. Manometric pressure measurements of $\mathrm{CO}_{2}$ in a precalibrated volume were used to determine the organic carbon concentrations. The ${ }^{14} \mathrm{C}$ dates of the soils were measured by liquid scintillation spectrometry at the Physical Research Laboratory (PRL), Ahmedabad (for details, see Yadava and Ramesh 1999). We assume 
that the soils are under a steady-state with respect to carbon cycling and, therefore, ${ }^{14} \mathrm{C}$ dates are assumed to represent the turnover times of SOC.

For stable isotope analysis of SOC, $\sim 1 \mathrm{~g}$ of dry soil sample was taken in a small quartz tube (outer diameter $9 \mathrm{~mm}$ ) along with pure $\mathrm{CuO}$ powder, sealed with quartz wool, evacuated, and heated at $\sim 900{ }^{\circ} \mathrm{C}$ for $\sim 1 \mathrm{hr}$ to produce $\mathrm{CO}_{2}$, which was purified cryogenically in several steps and its carbon isotopic composition $\left(\delta^{13} \mathrm{C}\right)$ was measured using a stable isotope ratio mass spectrometer (GEO 2020, Europa Scientific, UK) at PRL, Ahmedabad. The external precision for the $\delta^{13} \mathrm{C}$ measurements for the procedure followed is better than $\pm 0.2 \%$ (Laskar 2011). The accuracy of the measurements was checked by running an international standard (oxalic acid II supplied by the National Bureau of Standards, used as a modern reference for ${ }^{14} \mathrm{C}$ dating). The average $\delta^{13} \mathrm{C}$ (with respect to PDB) obtained is $-17.7 \pm 0.1 \%$, close to the internationally accepted value of $-17.8 \%$ (Laskar 2011).

For the soil texture study, about $30 \mathrm{~g}$ of sample was decarbonated by reacting with $10 \% \mathrm{HCl}$ for $\sim 8 \mathrm{hr}$, neutralized with distilled water to obtain $\mathrm{pH}=7$, dispersed with sodium hexametaphosphate to separate the clay coatings on sand grains, and sieved with a 2-mm mesh to remove gravels. Sands are separated with a mesh of size $63 \mu \mathrm{m}$. For grain-size distribution of clay and silt, the pipette method is used, where settling velocities of the components are calculated using Stokes' law (see Carver 1971 for further details).

\section{RESULTS AND DISCUSSION}

The alluvial sediment profile at BR has no clear horizons (Figure 2) and a fairly high clay content (30-70\%) (Figure 3). During flooding years, large amounts of fine particles are brought and deposited in the alluvial plain; therefore, this site has a large clay \%. In contrast to this, soil samples at $\mathrm{CH}$ show distinct layers with varying proportions of clay from $20-30 \%$ only (Figure 3 ). The bulk densities in both profiles are comparable, varying from 1.1 to $1.4 \mathrm{~g} / \mathrm{cc}$ and 1.2 to $1.5 \mathrm{~g} / \mathrm{cc}$ for BR and $\mathrm{CH}$, respectively. Usually, it is observed that SOC tends to increase with an increase in clay \% (Schimel et al. 1994; Rice 2002; Telles et al. 2003; Plante et al. 2006), which is clearly seen in the observed values, with the average $\mathrm{SOC}$ at $\mathrm{BR}$ being higher than $\mathrm{CH}$ (Figure 4). In $\mathrm{BR}$, at $\sim 50 \mathrm{~cm}$ depth where the clay content is the highest, SOC also has the highest value. The absence of the organic layer and modern carbon at the surface (Table 1) of BR is probably due to the frequent flooding in the region.
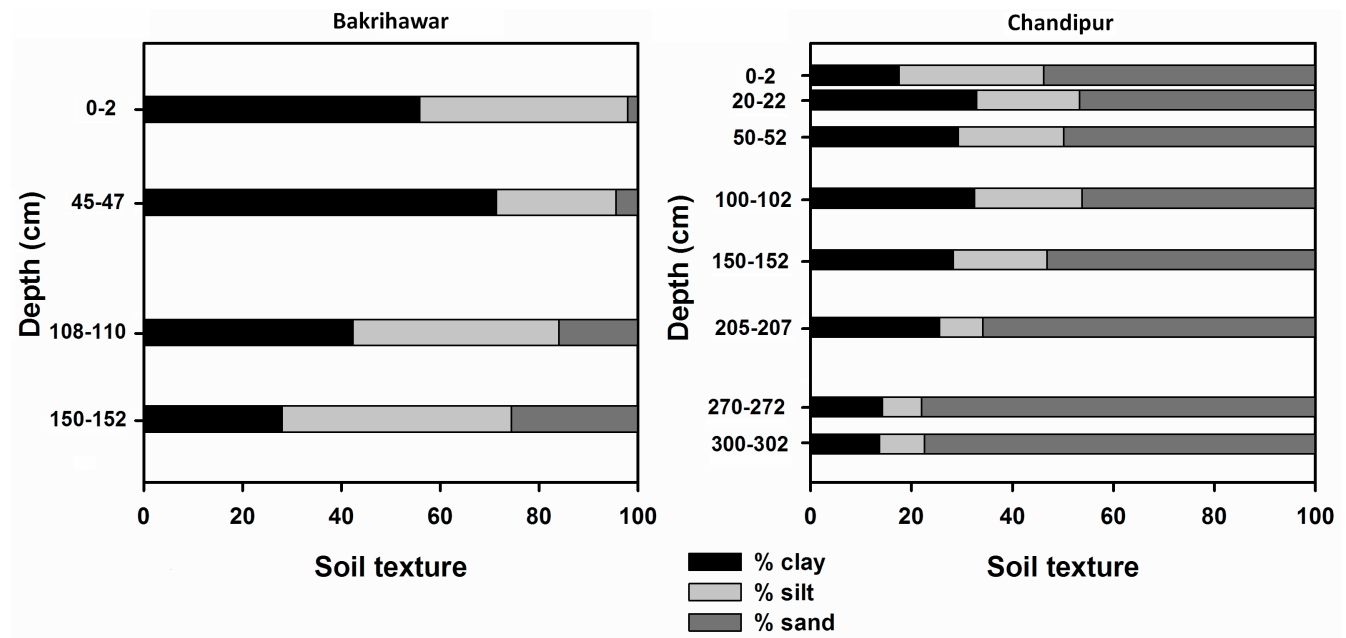

Figure 3 Distribution of clay, silt, and sand at different depths in the 2 soil profiles 


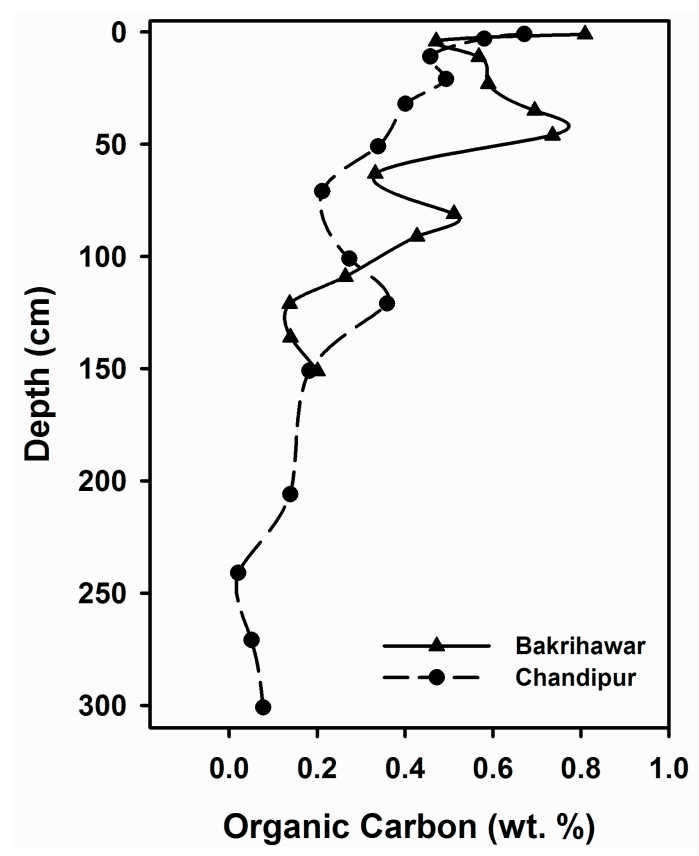

Figure 4 Variation of organic carbon contents with depth in the 2 soil profiles.

The $\delta^{13} \mathrm{C}$ values at $\mathrm{BR}$ are relatively enriched compared to $\mathrm{CH}$ (Figure 5). This can be explained as follows: the average $\delta^{13} \mathrm{C}$ of SOC at the surface in BR is contributed from 2 sources, 1) rice cultivation $\left(\mathrm{C}_{3}\right.$ type, $\delta^{13} \mathrm{C} \sim-27 \%$ ) and 2$)$ from grasses $\left(\mathrm{C}_{4}\right.$, measured $\delta^{13} \mathrm{C}=-11.4 \%$, Table 1$)$. Whereas at $\mathrm{CH}$, the surface vegetation is dominantly of $\mathrm{C}_{3}$ type (measured $\delta^{13} \mathrm{C}$ about $-28.6 \%$, Table 1 ). Therefore, the SOC percolating from the surface at BR should be enriched in ${ }^{13} \mathrm{C}$ relative to that of $\mathrm{CH}$. Another observation is that the highest $\delta^{13} \mathrm{C}$ value in $\mathrm{BR}$ (at $\sim 50 \mathrm{~cm}$ depth, Figure 5) coincides with the highest clay content. A similar signature was also observed by Becker-Heidmann and Scharpenseel (1989). This is thought to be due to the "chromatographic"-like effect in the soils; i.e. the clay with a complex binding with the old metabolized organic matter (due to microbial decomposition it has higher $\delta^{13} \mathrm{C}$ values relative to surface vegetation) does not get rejuvenated with the fresh organic matter (from the surface, having a $\delta^{13} \mathrm{C}$ value of the contemporary vegetation). This eventually percolates further into deeper layers with lesser clay content. Clay binds organic matter strongly and also favors the formation of aggregates, which protect against microbial decomposition (Feller and Beare 1997; Balesdent et al. 2000; Giardina and Ryan 2000; Rice 2002; Bradford et al. 2008; Manjaiah et al. 2010). This acts in 2 ways, first, the clay rich soil has higher SOC and second, it has less affinity for binding additional fresh organic matter. There is an enrichment of $>2 \%$ in $\delta^{13} \mathrm{C}$ with depth in both profiles in the upper soil layers $(0-50 \mathrm{~cm}$; Figure 5$)$. The probable reasons are (a) preferential decomposition of isotopically lighter molecules during microbial respiration (Ehleringer et al. 2000; Accoe et al. 2002) and/or (b) progressive $\delta^{13} \mathrm{C}$ decrease in the atmosphere during the industrial era due to emission of ${ }^{13} \mathrm{C}$-depleted $\mathrm{CO}_{2}$ from fossil fuel burning (Ehleringer et al. 2000).

The turnover time (or the mean residence time) of the soil carbon is defined as the average time spent by a carbon atom in the soil, from the time of its incorporation via photosynthesis and release back to the atmosphere by respiration/decomposition. ${ }^{14} \mathrm{C}$ ages of the bulk SOC, which accumulates 
Table 1 Organic carbon content, $\delta^{13} \mathrm{C}$ of soil organic carbon with respect to VPDB and ${ }^{14} \mathrm{C}$ dates of the samples from the 2 studied soil profiles.

\begin{tabular}{|c|c|c|c|c|}
\hline Sample & $\begin{array}{l}\text { Depth } \\
(\mathrm{cm})\end{array}$ & $\begin{array}{l}\text { Carbon content } \\
(\mathrm{wt} \%)\end{array}$ & $\begin{array}{l}\delta^{13} \mathrm{C} \\
(\% 0)\end{array}$ & $\begin{array}{l}{ }^{14} \mathrm{C} \text { age } \\
(\mathrm{yr} \mathrm{BP})\end{array}$ \\
\hline \multicolumn{5}{|c|}{ Chandipur (CH) } \\
\hline Vegetation & & & -28.57 & \\
\hline $\mathrm{CH} 1$ & $0-2$ & 0.67 & -27.95 & Modern $(100.4 \mathrm{pMC})^{\mathrm{a}}$ \\
\hline $\mathrm{CH} 2$ & $2-4$ & 0.58 & -26.66 & \\
\hline $\mathrm{CH} 3$ & $10-12$ & 0.46 & -25.93 & \\
\hline $\mathrm{CH} 4$ & $20-22$ & 0.49 & na & Modern $(102.6 \mathrm{pMC})^{\mathrm{a}}$ \\
\hline $\mathrm{CH} 5$ & $30-34$ & 0.49 & -24.41 & \\
\hline $\mathrm{CH} 6$ & $50-52$ & 0.40 & -24.02 & $780 \pm 80$ \\
\hline $\mathrm{CH} 7$ & $70-72$ & 0.34 & -24.75 & \\
\hline $\mathrm{CH} 8$ & $100-102$ & 0.21 & -24.91 & $1000 \pm 90$ \\
\hline $\mathrm{CH} 9$ & $120-122$ & 0.27 & -22.95 & \\
\hline CH 10 & $150-152$ & 0.36 & -25.04 & $1660 \pm 120$ \\
\hline $\mathrm{CH} 11$ & $170-172$ & 0.18 & -24.15 & \\
\hline CH 12 & $205-207$ & 0.14 & -25.55 & $3170 \pm 150$ \\
\hline $\mathrm{CH} 13$ & $240-242$ & 0.02 & -26.25 & \\
\hline CH 14 & $270-272$ & 0.05 & -25.27 & $4300 \pm 240$ \\
\hline CH 15 & $300-302$ & 0.08 & -25.39 & $4820 \pm 220$ \\
\hline \multicolumn{5}{|c|}{ Bakrihawar (BR) } \\
\hline Grass & & & -11.38 & \\
\hline BR 1 & $0-2$ & 0.81 & -22.29 & $480 \pm 70$ \\
\hline BR 2 & $2-5$ & 0.47 & -22.26 & \\
\hline BR 3 & $10-12$ & 0.57 & -20.08 & \\
\hline BR 4 & $22-24$ & 0.59 & -19.57 & \\
\hline BR 5 & $34-36$ & 0.69 & -18.09 & \\
\hline BR 6 & $45-47$ & 0.74 & -18.12 & $1290 \pm 90$ \\
\hline BR 7 & $62-64$ & 0.33 & -24.45 & \\
\hline BR 8 & $80-82$ & 0.51 & -21.09 & \\
\hline BR 9 & $90-92$ & 0.43 & -23.03 & \\
\hline BR 10 & $108-110$ & 0.26 & -22.70 & $3430 \pm 200$ \\
\hline BR 11 & $120-122$ & 0.14 & -22.35 & \\
\hline BR 12 & $135-138$ & 0.14 & -20.81 & \\
\hline BR 13 & $150-152$ & 0.20 & -22.71 & $3920 \pm 200$ \\
\hline
\end{tabular}

${ }^{\mathrm{a}} \mathrm{pMC}=$ percent modern carbon $( \pm 1 \sigma$ error $)$.

over a long period of time, do not represent the "true age" of the soil layer. In most cases, as it is an open system with a continuous supply of fresh organic matter, the estimated age is different from the true age. Therefore, at the most, ${ }^{14} \mathrm{C}$ ages of the $\mathrm{SOC}$ can be considered as minimum ages of the soil formation (Wang et al. 1996) and can be used to investigate the turnover time of SOC. Figure 6 shows the down-profile variation of ${ }^{14} \mathrm{C}$ ages at the 2 sites. At any depth, turnover time at $\mathrm{BR}$ is higher compared with $\mathrm{CH}$. This could be due to the relatively higher clay content at $\mathrm{BR}$. At $\mathrm{CH}$, the top soil layers up to a depth of $\sim 20 \mathrm{~cm}$ contain bomb carbon, indicating that a significant fraction of the organic carbon, added post-1950s, is still preserved in the upper soil layers. At BR, being an alluvial deposit, we do not see any reversal in the age stratigraphy (Table 1). As in flood years, BR is inundated and material from higher elevation is deposited, and old clay-rich organic materials from catchment mix with modern surface SOC, resulting in the finite non-zero age at 0-2 cm depth, about 500 yr BP (Table 1). 


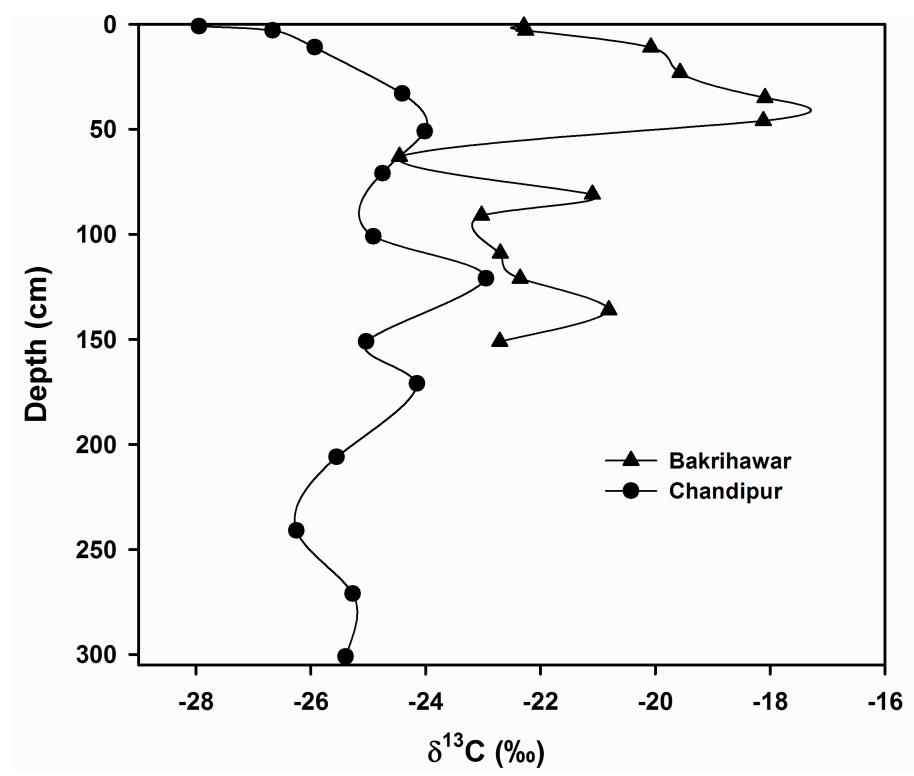

Figure 5 Depth profile $\delta^{13} \mathrm{C}$ of soil organic matter

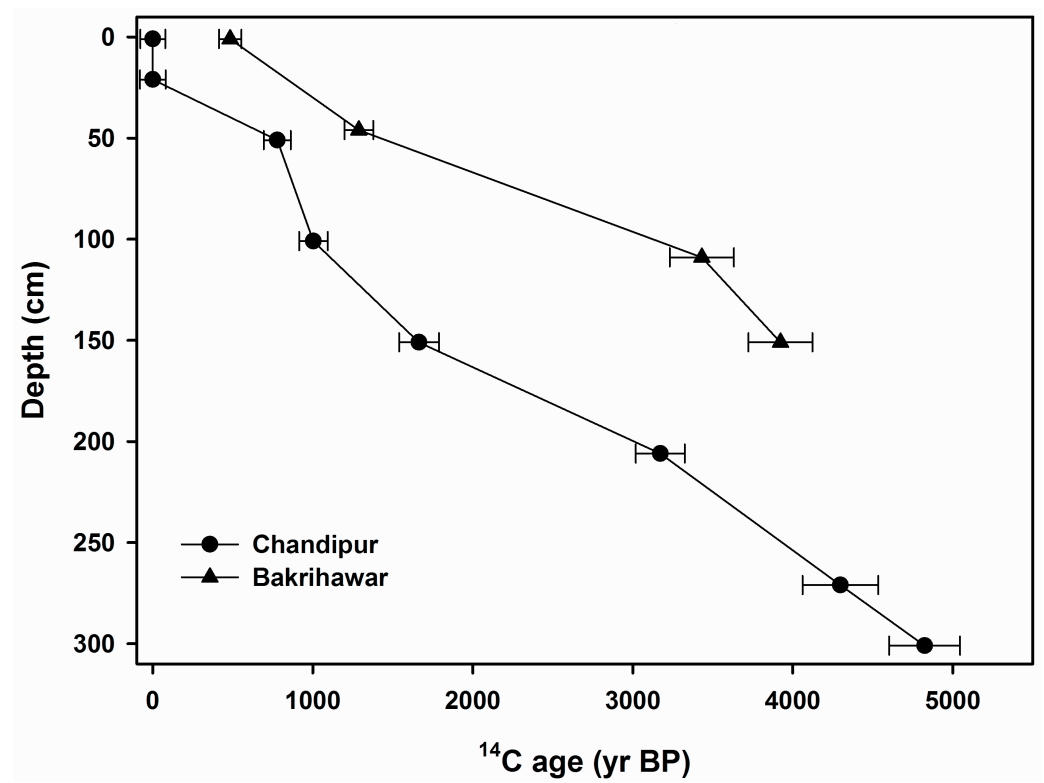

Figure 6 Variation of ${ }^{14} \mathrm{C}$ ages with depth. For pMC 100 or more, the ${ }^{14} \mathrm{C}$ age is taken as modern. Errors are at $1 \sigma$ levels.

Intense farming at $\mathrm{BR}$ started possibly in recent years. The effect of agricultural activity is prominently seen in the concentration profile of the SOC, as lower carbon contents in the top 2 to $50 \mathrm{~cm}$ layers due to the regular tillage, which brings up carbon to the surface and leads to erosional loss (Figure 4). 


\section{CONCLUSIONS}

Two soil sections from northeast India, an unexplored region from the soil carbon point of view, have been studied for their $\mathrm{SOC},{ }^{14} \mathrm{C}$, and ${ }^{13} \mathrm{C}$ inventories. The agricultural site has higher clay content and SOC due to the fluvial nature of its sediments. The highest clay layer in the agricultural site is associated with the highest SOC content and the most enriched ${ }^{13} \mathrm{C}$ of SOC. Here, due to the mixed contribution from rice cultivation and $\mathrm{C}_{4}$ grasses, $\delta^{13} \mathrm{C}$ values are found to be higher than that of the virgin soil. The turnover time of SOC in the subsoil is higher for the clayey alluvial sediments (Bakrihawar, BR) compared to the sandy soil of the hills (Chandipur, $\mathrm{CH}$ ), indicating that organic carbon associated with clay minerals are much more resistant to degradation.

\section{REFERENCES}

Accoe F, Boeckx P, Van Cleemput O, Hofman G, Zhang Y, Hua LR, Guanxiong C. 2002. Evolution of the $\delta^{13} \mathrm{C}$ signature related to total carbon contents and carbon decomposition rate constants in a soil profile under grassland. Rapid Communications in Mass Spectrometry 16(23):2184-9.

Balesdent J, Girardin C, Mariotti A. 1993. Site-related $\delta^{13} \mathrm{C}$ of tree leaves and soil organic matter in a temperate forest. Ecology 74(6):1713-21.

Balesdent J, Chenu C, Balabane M. 2000. Relationship of soil organic matter dynamics to physical protection and tillage. Soil and Tillage Research 53(3-4):215-30.

Becker-Heidmann P, Scharpenseel H-W. 1989. Carbon isotope dynamics in some tropical soils. Radiocarbon 31(3):672-9.

Biedenbender SH, McClaran MP, Quade J, Weltz MA. 2004. Landscape patterns of vegetation change indicated by soil carbon isotope composition. Geoderma 109(1-2):69-83.

Bostörm B, Comstedt D, Ekblad A. 2007. Isotope fractionation and ${ }^{13} \mathrm{C}$ enrichment in soil profiles during the decomposition of soil organic matter. Oecologia 153(1):89-98.

Bradford MA, Davies CA, Frey SD, Maddox TR, Melillo JM, Mohan JE, Reynolds JF, Treseder KK, Wallenstein MD. 2008. Thermal adaptation of soil microbial respiration to elevated temperature. Ecology Letters 11(12):1316-27.

Caner L, Seen DL, Gunnel Y, Ramesh BR, Bourgeon G. 2007. Spatial heterogeneity of land cover response to climatic change in the Nilgiri highlands (Southern India) since the last glacial maximum. The Holocene 17(2):195-205.

Carver RE. 1971. Sedimentation analysis. In: Carver RE. Procedures in Sedimentary Petrology. New York: Wiley-Interscience. p 69-94.

Deines P. 1980. The isotopic composition of reduced organic carbon. In: Fritz P, Fontes J, editors. Handbook of Environmental Isotope Geochemistry, Volume 1, Part A. The Terrestrial Environment. New York: Elsevier. p 329-406.

Ehleringer JR, Buchmann N, Flanagan LB. 2000. Carbon isotope ratios in belowground carbon cycle processes.
Ecological Applications 10(2):412-22.

Feller C, Beare MH. 1997. Physical control of soil organic matter dynamics in the tropics. Geoderma 79(14):69-116.

Giardina CP, Ryan MG. 2000. Evidence that decomposition rates of organic carbon in mineral soil do not vary with temperature. Nature 404(6780):858-1.

India Meteorology Department. 1999. Climatological Tables of Observatories in India 1951-1980. New Delhi: National Data Centre. http:/www.imd.gov.in.

Kohn MJ. 2010. Carbon isotope compositions of terrestrial $\mathrm{C}_{3}$ plants as indicators of (paleo)ecology and (paleo)climate. Proceedings of the National Academy of Sciences of the USA 107:19,691-5.

Laskar AH. 2011. Stable and radioactive carbon in Indian soils: implications to soil carbon dynamics [PhD thesis]. Udaipur: Mohanlal Sukhadia University, India.

Laskar AH, Sharma N, Ramesh R, Jani RA, Yadava MG. 2010. Paleoclimate and paleovegetation of Lower Narmada Basin, Gujarat, Western India, inferred from stable carbon and oxygen isotopes. Quaternary International 227(2):183-9.

Leavitt SW, Follett RF, Kimble JM, Pruessner EG. 2007. Radiocarbon and $\delta^{13} \mathrm{C}$ depth profiles of soil organic carbon in the U.S. Great Plains: a possible spatial record of paleoenvironment and paleovegetation. Quaternary International 162-163:21-34.

Manjaiah KM, Kumar S, Sachdev MS, Sachdev P, Datta SC. 2010. Study of clay-organic complexes. Current Science 98:915-21.

McPhearson GR, Boutton TW, Midwood AJ. 1993. Stable carbon isotope analysis of soil organic matter illustrates vegetation change at the grassland/woodland boundary in southeastern Arizona, USA. Oecologia 93(1):95-101.

Plante AF, Conant RT, Stewart CE, Paustian K, Six J. 2006. Impact of soil texture on the distribution of soil organic matter in physical and chemical fractions. Soil Science Society of America Journal 70(1):287-96.

Quade J, Cerling TE. 1995. Expansion of $\mathrm{C}_{4}$ grasses in the Late Miocene of Northern Pakistan: evidence from stable isotopes of paleosols. Palaeogeography, Palaeoclimatology, Palaeoecology 115(1-4):91-116. 
Raich JW, Schlesinger WH. 1992. The global carbon dioxide flux in soil respiration and its relationship to vegetation and climate. Tellus B 44(2):81-99.

Rice CW. 2002. Organic matter and nutrient dynamics. In: Lal R, editor. Encyclopedia of Soil Science. New York: Marcel Dekker Inc. p 925-8.

Schimel DS, Braswell BH, Holland EA, McKeown R, Ojima DS, Painter TS, Parton WJ, Townsend AR. 1994. Climatic, edaphic and biotic controls over storage and turnover of carbon in soils. Global Biogeochemical Cycles 8(3):279-93.

Sukumar R, Ramesh R, Pant RK, Rajagopalan G. 1993. A $\delta^{13} \mathrm{C}$ record of late Quaternary climate change from tropical peats in southern India. Nature 364(6439): 703-6.

Telles ECC, de Camargo PB, Martinelli LA, Trumbore SE, da Costa ES, Santos J, Higuchi N, Oliveira Jr RC. 2003. Influence of soil texture on carbon dynamics and storage potential in tropical forest soils of Amazonia. Global Biogeochemical Cycles 17:1040, doi: 10.1029/2002GB001953.

Thompson MV, Randerson JT, Malmström CM, Field CB. 1996. Change in net primary production and heterotrophic respiration: How much is necessary to sustain terrestrial carbon sink? Global Biogeochemical Cycles 10(4):711-26.

Torn MS, Swanston CW, Castanha C, Trumbore SE.
2009. Storage and turnover of organic matter in soil. In: Senesi N, Xing B, Huang PM, editors. BiophysicoChemical Processes Involving Natural Nonliving Organic Matter in Environmental Systems. Hoboken: Wiley. p 219-72.

Trumbore S. 2009. Radiocarbon and soil carbon dynamics. Annual Review of Earth and Planetary Sciences 37:47-66.

Wang Y, Amundson R, Trumbore S. 1996. Radiocarbon dating of soil organic matter. Quaternary Research 45(3):282-8.

Wynn JG, Bird MI. 2008. Environmental controls on the stable carbon isotopic composition of soil organic carbon: implications for modelling the distribution of $\mathrm{C}_{3}$ and $\mathrm{C}_{4}$ plants, Australia. Tellus B 60(4):604-21.

Wynn JG, Harden JW, Fries TL. 2006. Stable carbon isotope depth profiles and soil organic carbon dynamics in the lower Mississippi Basin. Geoderma 131(1-2): 89-109.

Yadava MG, Ramesh R. 1999. Speleothems: useful proxies for past monsoon rainfall. Journal of Scientific and Industrial Research 58:339-48.

Zhong W, Xue J, Zheng Y, Ouyang J, Qiaohong M, Cai Y, Tang X. 2010. Climatic changes since the last deglaciation inferred from a lacustrine sedimentary sequence in the eastern Nanling Mountains, south China. Journal of Quaternary Science 25(6):975-84. 